\title{
Basic Directions of Digital Production Development on the Basis of a Unified Information Model
}

\author{
Mokretsov Yu.V.* \\ Department of Administrative Disciplines \\ Vologda Institute of Law and Economics of the Federal \\ Penitentiary Service of Russia, Vologda, Russia \\ e-mail: warog@mail.ru \\ Kryukova D.Yu. \\ Department of Informatics and Mathematics \\ Vologda Institute of Law and Economics of the Federal \\ Penitentiary Service of Russia, Vologda, Russia \\ e-mail: magnyi@list.ru
}

\author{
Avdeev Yu.M. \\ Department of urban cadastre and geodesy \\ Vologda State University \\ Vologda, Russia \\ e-mail: avdeevyur@yandex.ru \\ Tesalovsky A.A. \\ Department of urban cadastre and geodesy \\ Vologda State University \\ Vologda, Russia \\ e-mail: andrew-tesalovsky@yandex.ru
}

\begin{abstract}
The article discusses the possibility of using information technologies in the forest industry, for example, the use of aerospace services, geographic information systems, as well as models of virtual enterprises that allow interactive, competent and timely decisions to increase the quality and accuracy of the forest fund and digital production management process. The information model is constantly being transformed by updating its geometry and attributes, replenishing with data generated at all stages of its life cycle and necessary for solving problems by specialists involved at a particular stage. The information model of digital production helps to solve the following problems in training: the training of students with the minimum necessary knowledge about the basics of process modeling in technical systems; promotes the assimilation of basic concepts, laws and modeling methods; contributes to the acquisition of experience important for practice activities: from the goal to obtain the result in the process of solving production problems; the formation in students of scientific thinking, a correct understanding of the limits of applicability of various laws of modeling, and mastery of methods for assessing the degree of reliability of results obtained using experimental research methods on models of production processes.
\end{abstract}

Keywords - Industry 4.0 concepts, forest industry, digital model of wood processing, sustainable environment development, green production, single information model.

\section{INTRODUCTION}

At present, it is difficult to maintain the pace of a developing economy and at the same time reduce the negative effects of industry and other human activities on the environment $[1,2]$. Therefore, for the best result in all areas, it is recommended to consider the development of virtual digital production and the environmental situation in the aggregate $[2,3]$.

The harmonious coexistence of the environment and the economy is an important issue in modern society. The development of financial instruments for environmental projects is one of the methods to ensure the existence of modern digital enterprises that do not harm the ecosystem [4-7].

In 2020, the development of three thematic priority goals is necessary: digital production; efficient use of resources and a low-carbon economy; environmental health and well-being. To achieve these goals, the role of eco-innovation and green financing is important to ensure that aspects of the priority task of resource-efficient and low-carbon digital production are met as the basis of the modern economy.

The consequences of the difficult environmental situation also negatively affect production in the form of increased costs, the difficulty of selling environmentally unsafe goods, threats to the safety of workers and employees of enterprises, depreciation of fixed assets and the possibility of their destruction, losses due to payment of environmental damage. In order to reduce the destructive impact on the environment and production, at the first stage it is necessary to find the sources of negative impact, assess environmental risks and develop methods to eliminate them. Therefore, in order to solve this problem, subject to a stable economic situation, any economic entity controls its potential risks and develops appropriate management methods. A system and methods for managing environmental processes integrated with greening production are needed. The concept of sustainable development in this direction can be defined as the maintenance and sustainable use of the functions (goods and services) provided by natural ecosystems and biosphere processes.

The instability of the economy already complicates the development and functioning of digital production in the framework of Industry 4.0; therefore, insufficient attention is paid to these issues that appear in the process of conducting business activities. The formation of environmental and production risks is due to the transition of environmental risks 
into economic ones when the environment responds to a source of risk. Therefore, their components complement each other. In the general case, environmental and economic risks are risks of economic losses, damage arising from various business entities due to environmental degradation. Among their main features, the following are distinguished: environmental and economic risks are associated with damage to both the business entity and other enterprises, the population as a whole, the animal world, life and health risks of the population, which may occur not only during the direct occurrence of negative impacts, but in the future, and it should be taken into account in the strategic planning of the enterprise. The need for a green economy today does not require special comments. In our opinion, the introduction of the principles of the green economy and environmental innovations in the woodworking industry as the main mechanism for the implementation of environmental and economic policies to achieve the principles of sustainable development should include, first of all, the reproduction mechanism of the green energy as a basis for the production of goods and vital activities of the population.

The current level of development of digital production is called Industry 4.0, the main element of which is digitalization, which includes digitalization of production, the use of "smart" technologies, the creation of "virtual twins", etc. The global trend is the creation of scientific and production clusters based on global industrial networks, the concept of a reasonable environment, the "Internet of things", "Big data" and "Smart production". Modernization and implementation of digital technologies can ensure the development of industry, localization and strengthening the competitiveness of Russian enterprises. The development of this sector of the economy is carried out by the government at the legislative level. Back in December 2016, the President of Russia instructed the Federal Assembly to prepare a program for the development of this sector of the economy. The program for the development of the digital economy in Russia was adopted on July 6, 2017; the main postulate of this document is the full integration of the Russian virtual economy with this area of the Eurasian Economic Union. The state undertakes to create all the technical and financial conditions for the speedy progress of the new manufacturing industry.

\section{RESULTS}

Today, nine drivers are identified that have a major impact on the development of the concept of Industry 4.0 as the basis for the development of digitalization of production, including:

- self-managing robots and complexes;

- additive manufacturing;

- augmented reality;

- computer simulation of equipment, materials and manufacturing technologies;

- horizontal and vertical system integration;

- industrial "Internet of Things";
- cloud computing;

- Information Security;

- "Big Data" and analytics.

Currently, without the use of digital technologies at enterprises, it is practically impossible to achieve a technological breakthrough, since it is automation and saturation of information that provides real competitive advantages. This will allow switching to fully digital production and using information and automated technologies along the entire value chain. Examples of modernization and implementation of digital technologies are PLM systems (product lifecycle management) and BPM systems (business process management). PLM unites methods and means of product information support at all stages of the product life cycle. PLMs are the base integrating the information space in which CAD, ERP, PDM, SCM, CRM and other automated systems interact. The development of CAD systems led to the emergence of the concept of BIM (building information model) - an information model of a building/structure, which, in conjunction with GIS technologies, actively integrates with such high-tech phenomena as the Internet of Things and Augmented Reality when informatization penetrates the physical essence of objects and phenomena forming a system of a closed life cycle. The development of BIM systems is directly related to the "Multi-D" design - the life cycle management technology of a complex engineering facility. This stage of development of the digital economy provides for a review of the principles of organization of production processes and their management.

In the last two decades, almost simultaneously and in parallel with information modeling of buildings, as the initial stage of digitalization of production, another, but - from a completely different point of view-conceptual approach to creating new objects, has been successfully developedSustainable Design.

This concept, which has received the widest dissemination in the world, refers to the general concept of Sustainable Development and, in essence, is simply doomed to close interaction with BIM technology. That is, "green" designing is not just designing in its usual sense, but also setting optimal parameters for the future operation of the building throughout its entire life cycle. Currently, environmentally sound design in the world is being stimulated through several existing standards or, more correctly, rating systems (the so-called "green ratings"), designed by means of public opinion to encourage developers and manufacturers to take the path of more rational environmental management.

Today, in business, in parallel with the real environment in which the enterprise operates, a virtual world is being created. A series of experimental studies is carried out related to simulation of the life cycle of the enterprise itself, its products and market activities. In the foreign economic sphere, the virtualization space includes such concepts as the electronic market, electronic commerce, virtual product, virtual production, virtual factory, virtual bank, and, of course, virtual organizations (enterprise, corporation) as a whole. 
Creating a unified information environment for digital production, including operational, construction, design, engineering, repair, scientific and research data for each stage, will minimize organizational, functional, informational and financial gaps and ensure effective asset management throughout its life cycle. So far, these systems are mainly recommendatory in nature for newly created or reconstructed buildings, when designing the building's infrastructure and other issues, and certification on them is voluntary.

Three-dimensional design in the process of organizing production allows creating a virtual (electronic) layout of an object, on the basis of which you can check the consistency of the model and form the basic drawings, get the source data for calculations and related tasks. Information integration consists in the fact that all automated systems used at various stages of the life cycle operate with various information models that describe the product, its production and use technologies. Through an integrated information environment, paperless information interaction is carried out between all participants in the product life cycle. Currently relevant is an integrated information structure with continuous support for the process of ensuring the product life cycle in digital production. Therefore, the CALS-technologies (Continuous Acquisition and Life-cycle support) of end-to-end support of products at all stages of its life cycle from marketing to disposal of products, due to the information interaction of all participants in the life cycle of each product, ensuring its creation, manufacture and implementation are being developed. The implementation of CALS in practical terms involves the organization of a single production information space, combining automated systems designed to effectively solve the tasks of engineering, planning and management based on a single information model Fig. 1.
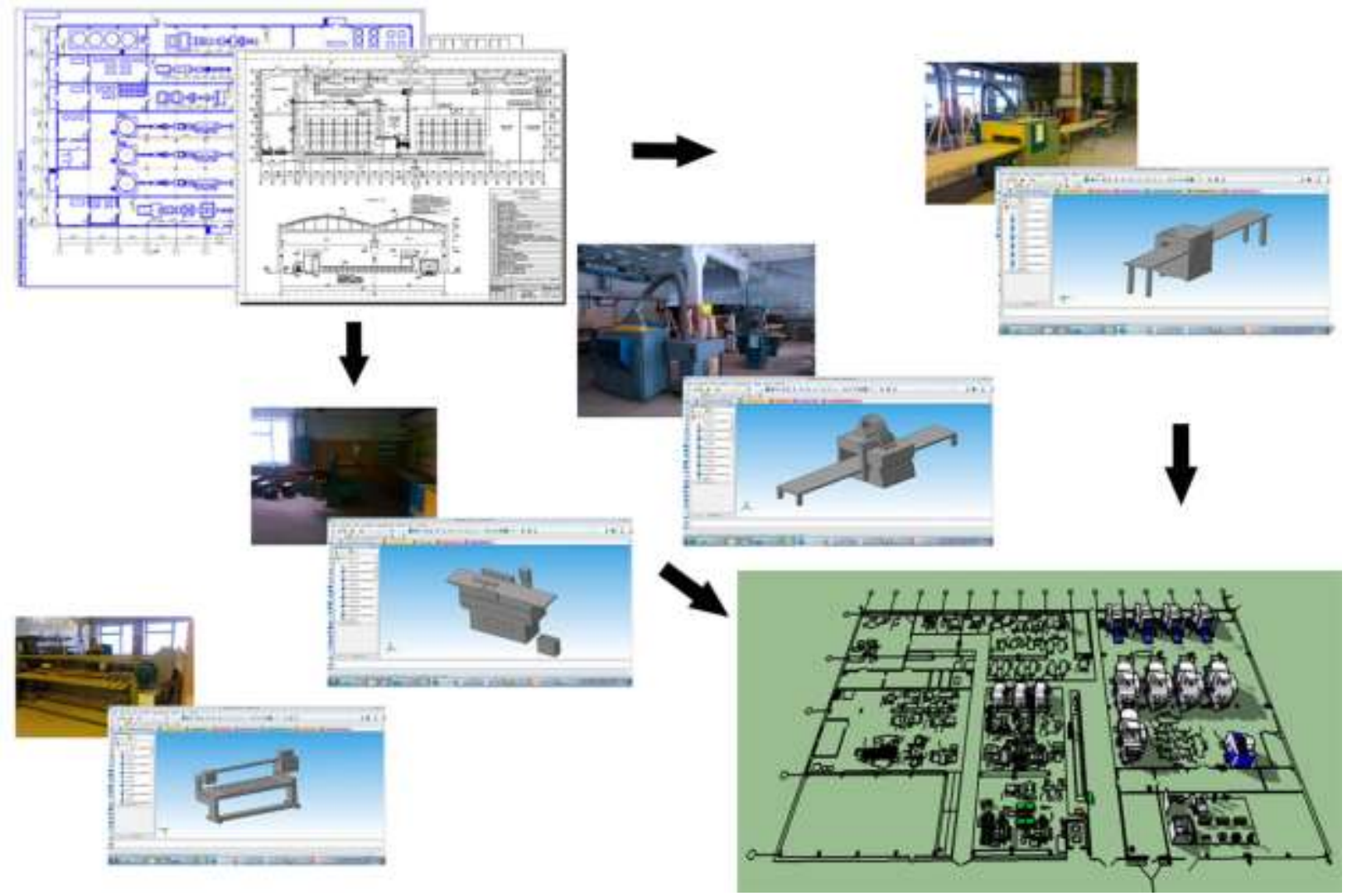

Fig. 1. A single information model for the design and management of the woodworking production process

\section{DISCUSSION}

To maximize the optimization of the logging process, automated remote monitoring systems, logging management systems and automatic collection of information on the distribution of working time, output and equipment operation mode are being developed. It is necessary to create a unified forest information model that reflects complete, reliable and relevant information on the state, quality and dynamics of forest ecosystems for application in the decision support system. Thus, the most important characteristic of a virtual organization is a flexible, adaptive, dynamic network structure. Since such a network does not exist in the real physical space, but is created through the information integration of resources.

Information support of forestry processes consists in analyzing, describing, modeling business processes, saturating the database with updated information on forest ecosystems and combining all the data in a single management center. The purpose of modeling is to create an informational context that provides organizational management processes for the timber industry. In this regard, decision support methods based on simulation modeling and mathematical programming are of particular importance, and this support, in turn, allows making 
the right decisions that lead to the optimization of the forest fund structure.

The main problem of the continuous sustainable development of the forest industry is the lack of an integrated approach to creating a single information model. The basis for creating an information model can be automated systems ArcGIS/ArcPad GeoDraw/Geograph, Maplnfo, Arc/Info, Topol data collection and terrain mapping. For example, there is a whole line of domestic developments, such as the "Sectorial Automated Forestry Management System of Russia" (All-Russian Research Institute of Forestry and Forestry Mechanization); "Automated Forest Management System" (Karelian Research Institute of Forestry Complex of PetrSU), etc. Real-time technical means and equipment are needed for forest monitoring: systems: video surveillance, thermal imaging sensors, small drones, as well as modern Internet capabilities —online broadcasting in real time from Google Earth.

Advantages of the use of geographic information systems (GIS): a virtual map-model of the city with the production facilities indicated on it and the ability to quickly obtain information on them is much more visible and effective is an integral stage of modern digitalization of data, monitoring, automation and optimization of processes, which, in turn, requires modern smart models and systems.

\section{CONCLUSIONS}

As a result of the analysis of heterogeneous software used in the industry, it can be concluded that at the moment there is no basis for creating a unified centralized forestry information system in Russia, with the organization and maintenance of combined databases, changes, business planning and reporting based on automated document management and storage in a special database management system.

Thus, it is necessary to develop highly intelligent digital systems and decision support systems in the forest industry aimed at the maximum optimization and automation of production and management processes. In connection with optimization in the forest segment, mining and production are helped by aerospace forest analysis services, which make it possible to quickly evaluate the volume and quality of the cutting area for planning production volumes. Accurate and up-to-date information is important for the prevention, detection, monitoring, reporting and, ultimately, the suppression of forest crimes.

Information support of engineering business and production processes consists in analyzing, describing, modeling business processes, saturating the database with updated information on production systems and combining all the data in a single control center - the geographic information system of industrial parks, technology parks, clusters. The purpose of modeling is to create an informational context that provides processes for organizational production management. In this regard, decision support methods based on simulation modeling and mathematical programming are of particular importance, such support, in turn, allows making the right decisions that lead to the optimization of the structure of modern digital woodworking production.
The transition to a digital representation of production facilities opens up new opportunities and allows the following problems to be solved:

- creation of three-dimensional models of production infrastructure;

- comprehensive presentation of the project, including the ability to prepare several project options in 3D;

- planning and development of various options for the development of production in real time;

- analysis and evaluation of production facilities;

- presentation of the results of the analysis of production in a convenient form for perception.

The information model must be constantly transformed by updating its geometry and attributes, replenishing the data generated at all stages of its life cycle and necessary for solving problems by specialists involved at a particular stage. The digital production information model helps to solve the following tasks in training:

1. Forming in students the minimum necessary knowledge about the basics of process modeling in technical systems;

2. Promoting the assimilation of basic concepts, laws and modeling methods;

3. Promoting the acquisition of experience important for practice activities: from the goal to obtain the result in the process of solving production problems;

4. Forming in students scientific thinking, a correct understanding of the limits of applicability of various laws of modeling, and mastering methods for assessing the degree of reliability of results obtained using experimental research methods on models of production processes.

\section{References}

[1] D.A. Amandykova, Z.A. Imanbayeva, A.M. Assylbekova, L.T. Nurkusheva, I.I. Ostapenko, "On the history of studying museum complexes, Astra Salvensis, vol. 11, p. 311, 2018.

[2] L.T. Nurkusheva, Z.A. Imanbayeva, O.O. Karpechenko, "Construction of an object design element from the perspective of utility", Int. J. of Appl. Engineer. Res., vol. 10, no. 20, pp. 41032-41037, 2015.

[3] Y.M. Avdeev, S.M. Hamitova, A.E. Kostin et al., "Assessing the Properties of Tree Trunks in Forest Phytocenoses Depending on the Soil and the Climatic Conditions on the Territory of the Taiga Zone of the European North of Russia”, J. of Pharmac. Sci. and Res., vol. 10, no. 5, pp. 1288-1291, 2018

[4] S.M. Khamitova, A.P. Glinushkin, Yu.M. Avdeev et al., "Assessment of microorganisms and heavy metals' content in the soils of arboretum named after Nikolai Klyuev", Int. J. of Pharmac. Res. and Allied Sci., vol. 6 , no. 3, pp. 47-55, 2017.

[5] S.M. Khamitova, A.P. Glinushkin, Yu.M. Avdeev et al., "Condition assessment of tree plantations and phytosanitary properties of soils in cedar groves", Int. J. of Pharmac. Res. and Allied Sci., vol. 6, no. 4, pp. 1-7, 2017.

[6] A.N. Naliukhin, A.P. Glinushkin, S.M. Khamitova, Yu.M. Avdeev, "The influence of biomodified fertilizers on the productivity of crops and biological properties of soddy-podzolic soils", Entomol. and Appl. Sci. Letters, vol. 5, no. 3, pp. 1-7, 2018.

[7] A.V. Kozlov, I.P. Uromova, N.N. Koposova et al., "Optimization of the Productivity of Agricultural Crops at Application of Natural Minerals as Ameliorants and Mineral Fertilizers on Sod-Podzolic Soils", J. of Pharmac. Sci. and Res., vol. 10, no. 3, pp. 667-680, 2018. 